\title{
EL MAGISTERIO DEL MITO (A propósito de Antonio Machado)"
}

\author{
Antonio Sánchez Trigueros \\ Universidad de Ciranarla
}

¿Qué hat ocurricle eon un poeta como Antonio Machate cuyos versos, cualesquiera (que fuesen. podian convertirse en un calsi himmo de commión resistente, dentro de un tipo de actos calificaddos sistemáticamente de subversivos por la palsada dictadura'?

Quizás algunos opinen que en esta mesal redonda sobre «til magisterio de Antonio Matchadom el contenido de mi intervención no es el más pertinente, pero estoy convencido de que en la celebración de cualquier efemérides relativat a un poeta tan utilizade y manipulado como Antonio Machado, se debe reservar al menos un hueco sonde tener la posibiliclad de reflexionar críticamente sobre la significalción social sle su figura. sobre lo que representa aún para el hombre de hoy. sobre lo que para muchos ha side y sigue siendo el verdadero magisterio del poeta de Cemmos de Castilla. Mis palabras, pues, estatán encaminalas a indagar en lo que se esconde bajo una adniración acrítica, muy generalizadla todavía, hacia la persona

\footnotetext{
$\therefore$ Este lexto reproduce mi intervención en la mesa redenda (pue. bajo el título de "ll magistero di Antonio Machado", se ceelebó en el Convegno Intemazionale "Antonio Machade verso l’Europal" (Torino, 18-22 de febrero de 199()) y que compantí con Francisco Brines. Carles Sahagén. Manmel Día\% Martiney y' Luis (ialtéa Montero. Una versión anterior de este trabajo la di a conocer en otra mesa redonda. "An1onio Machado aujourd'huim, organizada en el Colegio de España, de París, el 3 de noviembre de 1988. en la que participaron también Serge Salain, Carlos Serrano, Bernard Sesé. Jorge Urrutia y Mannel A. Vázquez. Meclel. La primera versión, muy breve, fue expuesta en público en 197.5 en la facultad de Fïlosofía y Letras de la Universidad de (iranada, en un acto organizado con molivo del centenario del nacimicmo (lel poeta y corrio de mano en mano fotocopiada junto con las otals intervenciones, ninguna de las cuales iba firmada por molivos obvios en alyuellas fechals.
} 
de Antonio Machado, que puede lalsear la lectura de su obra y enmascarar su verdadera ratzón histórica, si es esal razón la que nos interesa conocer.

Hace unos años Juan Goytisolo, en un esclarecedor arlículo sobre las alsombrosals coincidencias de Machado con las diatribas de los dirigentes sesviéticos contra Joyece y el arte de vanguardia, comenzaba aludiendo al «proceso de beatificación del escritor emprendido por muestros actuales programadores culturales» y añadía unas líncas más abajo: "cl culto, no sé si de dulía o de latría, que con lines interesados se le profesa resulta a todas luces grotesco e inapropiato: entre el ostracismo francpuista y la devoción religiosa de Alfonso Guerra media un ancho campo en el (pue la noble figura del poeta puede y debe ser contemplada sin anteojeras ni prejuicios» (Cioylisolo, 1985: 20).

A la altura de estos momentos finales de la celebración del cincuentenario de su muerte, podemos alirmar que el fenómeno de la veneración al hombre y al poeta ha vuelto a resurgir con fuerza desde un estado de latencia vivo y constante; las citas que iré intercalando en el texto son cjemplos significativos de ello y puras muestras de un discurso que a lo largo de los años se ha vuelto habitual entre la crítica machadliana. Adelanto ya que hay ocasiones, incluso, en que se detecta correctamente el problema, pero se vuelve a la solución consabila de sumar biografía y poesía y considerar la obra como transparencia de una vidla cjemplar: "No acierto a explicarme -escribe el profesor Pozuelo por yué los españoles de hoy estamos homenajeanclo más una biografía y un talante que una obra $|\ldots|$ Somos capaces incluso de venerar en más alto grado lo uno que lo otro, siendo así que en Machado tamaña separación es un disparate $[. . . \mid$ Siempre ha habido en los lectores de pocsía un afán de correspondencia entre vida y obra cue muy pocas veces se da pero gue en Antonio Machado deviene emblemática. Lin la triunfante posmodemidad, cuando los lazos de lal correspondencia se desdibujan porque adquiere mayores dimensiones el hilo del fingimiente y la máscara, nos resistimos a renunciar del todo a esa lección de autenticidad vital que su figura enseña» (Pozuclo Yvancos, 1989: 7).

I as consideraciones que presento aquí se silluan dentro (ee lo (jue desde hace algún tienpo trato de plantearme como una historia de los mitos poéticos del siglo XX, en un esfuerzo por conseguir desmontarlos como tales, de forma que se coltienda que esa mitificación no desemboca en una lectura pura, evidente, objetiva del poeta, sino en la que, como todas las posibles, sería una lectura no inocente, ideológica e interesada, que reduce a una milagrosa unidad lo que no es sino entramado real de contradicciones. Algún adelanto de estas reflexiones he ido dando en otros ámbitos, la última vez en la mesa redonda organizada por el Colegio de España de París, el 3 de noviembre de 1988. Parece que el tema interesó a juzgar por la utilización que, sin indicar su procedencia, se ha hecho de estas ideals en algún artículo publicaclo clespués.

Antes de pasar adelante quiero dejar muy claras dos cuestiones: primera, que yo tambićn me considero partícipe de esa lectura mitificaldora por aquellos años en que las condiciones de la vida española obligaban a una distorsión sistemática de la realidad y el nombre de Antonio Machado era utilizado como arma arrojadiza contra la dictadura; y segunda, que no pretendo que se olviden unos comportamientos humanos ejemplares como si no hubieran existido, sino que la natural admiración que producen no se proyecte sobre la interpretación de su obra. Por eso, desde el más profundo respeto hacia las actitudes vitales del poeta de Soledades voy a hacer una serie de reflexiones a través de las cuales esbozarce el mecanismo mitificador que se esconcle bajo una admiración indiscriminada o parcial hacia un hombre y un pocla que, como tantos otros hombres, sufrió a España hasta la mucre. 
La pregunta de partiela sería la siguiente: ¿cómo se produce y articula el mecanismo que ha dado como resultado la mitificación de Antonio Machado?

Fin primer lugar, desde una visión positivista, en la (pue el conepto ideológico de sujeto es afimaldo como principio y centro explicativo de ha historia, en Machado se ha buscado y se ha descubierto a un hombre, una existencia real, que odavía por su cercanía histórica calsi podemos tocar con las manos, que en verdad ha vivido, algo material gue ha dirigido imperativa y plenamente su destino. No en vano muchos trabajos sobre el poeta sevillano van encabezados por esa frase (jue escribió en Madrid en agosto de 1936, puesta en labios de Juan de Mairena: "por mucho que valga un homber munca tendrá valor más alto que el valor de ser hombre».

Así, se ha considerado que escribir sobre Antonio Machado no es escribir sobre cualquicra y ello, por tanto, entranaría una grave responsibilidad, porque use rata de uno de los casos de mís perfecta compenenación de obra, hombre y tiempo $|\ldots|$ se trata de diversas dimensiones del vivir fundidas en una unidad: el hombre Antonio Machadon ('luñón de Lara, 1967: 7-8). Y en otro lugar se afirmaba: "¿Qué significa Machado para Fspaña? |... fue un gran poeta $[\ldots \mid$ fue un pensador sin alharacas $|\ldots|$ Pero fue, sobre todo, un hombre bueno, (jue llevó su inteligente bondad -liecha de comprensión y renunciación. - hasta cl heroísno) personal; mantuvo siempre una actitud vital basada en la autenticidad consigo mismo. con lal vislat y con el munclo. Y, por lodo ello, en la crisis más grave de la existencia española en lo que va de siglo XX, lo mejor de España se llamó Machado; y nostálgicamente, lo mejor de España sigue todavía llamándose Machado» (Giil Novales, 1966: I1). Aún el pasado año el prolesor Díez de Revenga ha insisticlo en que uel signo más permanente de la poesía de $\Lambda$ ntonio Machado es el de lat atuenticidad |... | auténtico en sus comportamientos y auténtico en su poesía, desde el principio hasta el fimal |... en estos pocmas finales patéticos la atutenticidad machadiana brilla con una luz mucho más lulgurante $|. .$.$| y fue auténtico en su pensa-$ miento |... La autenticidacl que ennobleció su vida $|. .$.$| emoblece hoy |\ldots|$ toda su poesía» (Díe\% de Revenga, 1989: 3). Li milo se ha ido perfilando: a la existencia real se unen fundamentales cualidades de bondad, comprensión, renunciación, autenticidad.

Fs significativo y revelador que muchas de las claves de la mitificación de Antonio Machado se encuentren en su "atutorretrato», espacio textual de indudable atracción persuasiva. Como sabemos, Machadlo se presenta ahí como más précoupaclo en ser hombre (mamo viril) que en ser poeta; y si como hombe se considera hueno, como poeta se considera auténtico, porque su poesía es voz no éen. vo\% del hombre que siempre va con él; y a la bondad une la comprensión (su verso brola de manamial seremo), la filcmeropía, su amor al hombre, y, por otra parte, su remuncia es total, por(pue la muerte lo atrapará ligeres de épuipreje y completamente desmudo, como los hombres más puros, los de la mar. Precisamente sobre el poemal "Retrato» Rafael Conte decía hace un año: "Fis la virtud de la gran poesía de todos los liempos: nos pone las palabras en la boca y ya no tenemos más remedio (jue seguir pronunciándolas sin parar |... Su vida, serena y derramada, su sencillez, su incréble bondad, su alta moral y su excelsa ética civil se plasmaron en una poesía cuya exactitud, precisión y fácil comprensión rivalizan con una densidad expresiva casi milagrosa |... | expresión (le nuestro inconsciente colectivo |quel forma parte de la entraña le España, pues su poesía se chearnó para siempre en la historia de su pueblon (Conte, 1989: 2).

Pero para la configuración del mito no basta con yue sea hombre y sea bueno; y es que en este caso es también muy importante su desalino, su existencia gris, su moderada bohemia. su vida hasta cierto punto vulgar gastada en capitales y ciudades de provincias, una vicla 
sin especiales estridenciass y cumplida en un trabajo diario y normal. porefue todo ello sitúa su existencia al alcance de todos, como algo gue nos podemos tropezall por la calle y con to

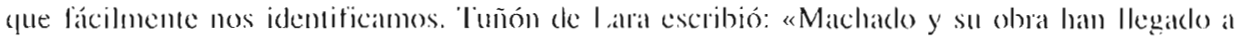
ser algo personal de cada uno, algo (que se integra en nuestras emociones, nuestros pensamientos, nuestras escalas de valores» (Thunón de I.ara. 1967: 7); y Juan Molina afirmaba hace unos meses: "Vivió el poela una entrega sin límites a su entorno y huyó, tímielo eterno, de

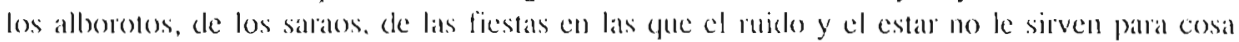
diferente que distaterle, distorsioníndole, de su quehacer, de su mundo, (pue no es otro gue el mundo (lel hombre en justicial y' en libertad" (Molina, 1989): 29).

Fis el mito al alcance de todos. más todavía cuando para algunos Machado sicmpre allirmó su independencia, su no affiliación a partido alguno, su no deber nada a nadie. Fes una variante en la secuencia constructiva del mito producida por las interpretaciones que han considerado su persona y su obra como paradigmas del diálogo: recordemos lo gue val descle la revalorización de Antonios Machato (uel poeta rescatado», de Dionisio Ridruejo, 1940) por parte de lat revista liscorical. la revista falangista de la immedialta posguerra, hasta las advocatciones a Machado de la revista (inedernos para el Diálogo o las provenientes del crislianismo progresista, cuando se relacionan textos del poeta con escritos de los papas recientes Juan XXIII o Palblo VI. Y se decía: "(puizás el único personaje que ha enlarado en un común respelo a personals de ideologías muy diversass sea Machado. |que constituye el ejemplo de ver-

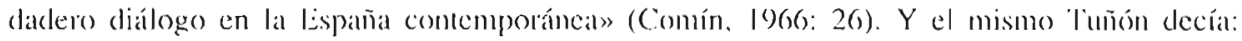
«Precisamente, en la más rigurosa urgencia de nuestro liempos. la del diálogo, se perfila la figura señera de don Antonio, (ule supo comprenderla con la sensibilidad de guienes van por (lelante de su tiempo" (Tuñón de Lala. 1967: 320). Lis. pucs, ésle el Machado hombre, bueno, encarnación de una estética esencial de la unidad, sujeto trascendental no dividieto, gue es capaz de unir espiritualmente apuello que sólo en el nivel de lo emprírico y material permanece escindido.

La otra variante de este punto de la secuencia está construida por la posición que, desde otro lugar ideológico, no comparte esa variante del Machado dialogante, ecléctico o aséptico, en cuanto que desde este lugar lo determinante en esa personalidad humama, bondadosa, cercanal de andlar por cassi, serían sus gotas de sangre jacobina, su constante compromiso histórico con una de las Fspañas en conflicto, su carácter crítico y progresista. sus últimos y definitives compromisos, su lucha verbal en las tribunas-trincheras de una de las Fspañas de la guerra civil, su carácter representativo de esa esencia vagamente socialista, heredada de la Institución Libre de Finseñanza y adlicta a la personalidad de Pablo Iglesias, y finalmente su muerte en uno de los lados de la contienda, donde su existencia aparentemente vulgatr se agiganta hasta la altura de los mártires; una muerte considerada como supremo acto de autenticiclad, de verdid, de renuncia, magna conliguración (iel héroe, anles oscuro, ahora iluminado, que sucumbe, que cace, pero sólo provisionalmente, en cuante gue se considera que su espíritu se reencarnará vivamene en las mevas generaciones de luchadores. Fis la semilla a la que alude Finma Rodrígue\%: "Y Antonio Machade es como la simiente, una simiente de la cue resulta imposible calcular los frutos porgue éstos se han multiplicadlo y reproducido saltankio los límites (lel monentome (Rodrígue\%, 1989): 3()).

Vistas las dos variantes, sigue la secuencia. Porque algo esencial falta en la alureola ded mito y ello es su acción poética. Si como ser material lue sencillamente vulgar, como espríritu se revela como algo especial, elevado, intérprese de los dioses, sean los de arriba o los de abajo, visionario, espíritu cue hablis por unos o por otros, los dialogistas o los particlistas, el 
ser espiritualmente privilegiado, el vidente, el poseedor del más allo conocimiento intuitivo; en suma, el Poetat capar de versos casi milagroses, como escribía Conte.

Clato que en sus raíces el mito Antonio Machado no nace de la obra, simo de la persona; no nace del Machadlo escritor, gue queda subordinade al Machado hombre, cuyal poesía, entendida siempre como maravillosia constallación de las virtudes del elegido, sería en última instancia accidente, puro reflejo o emanación, músicica puestil al servicio de la letra de su vida, músicat que, melodiosal y sentimentalmente, ritma un mensaje aleccionator; es el contenido determinante coronado con el envoltorio de la forma artísticat. Y es que lo importante en el mito Machado, desde el punto de vista de su génesis. es que tiene vida, en el sentido que proporciona un modelo a la conducta humana y confiere por eso mismo signilicación y valor a una existencia, ya se piense en existencia no diviclicla o en existencia clesartaigada (cfi. M. I:liade, 1968: 14). Ls decir, el mito en cuestión proporciona un modelo de comportamiento y fija la conducla del hombre tras dar unal respuesta determinada a sus problemals; además el mito ofrece un sentido trascendente a la existencial y. de hecho, la pretensión de dar un sentido acrítico a la existencia es to que caracterizal estrictanente al mito religioso (cfr. Paramio. 1971: 3.5).

Fin efecto, he dicho «religioso». i.Acalso Antonio Machado, a partir de su mitificación, no se ve aupado a una casi grotesca (iloria de Bernimi malterialista? ¿Es que no queda conformado como una especie de santo laico, venerado en capillas más o menos progresistas? ¿Y ese Machade no ha surgiclo a partir de la misma conciencial mítica que ha producido el lilos Sunctortum?

Yal estí, pues, colocialo el pocta sevillano en el lugar de lo sagrado e intocable, que hatcen posible palabrass tan enlierecidas y cscatológicas como éstas de Martínè Sarrión: "las torpes pellas contra la immensal estatura de Machado hace muchísimo tiempo (jue se secarron y desprendieron sin tocar una sola libra de su altisima condición de poeta y de hombre $|. .$.$| y$ cuando las minúsculas deposiciones lírico-metalísicas $|\ldots|$ de los sedicentes patricios $\mid$... $\mid$ sean un chuseo y prescindible episodio de las letras |... Antonio Machado, fallecido y sepulto en el exilio late 50 años y fresco hoy en su obra como rosa de abril, no precisastá ni de una asspirina en el agua para scguir conservando la lozanía» (Martínc\% Sarrión, 1989: II). Fxpresiones éstals que contrastan agudannente con las de todos aquellos que, como Guillermo (annero, han denumciado razonablemente la utilización de Machado para condenals, negaciones y desprecios: "Machado sirvió palla censumar al Modernismo, a la vanguardial y a la generación del 27, y ya en la postguerra, amparándese en la bandera de Machado, se pusieron en marcha las peores retóricas. Es un autor respetable, pero también responsable de las aberraciones que se conctieron en su nombre» (cit. en Iglesias, 1989): xiv). Ya José A. Valente dio en el centro)

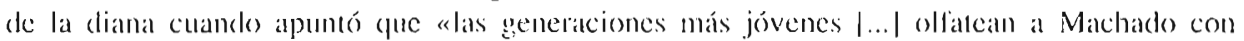
alguna desconfianzal |... lo gue lal vez recusen en Machado no sea Machado mismo, sino más bien sucesivals imágenes de éste (jue ellos ya no (juieren llevar, y están en lo justo. en procesiones más o menos heredadas» (Valente. 1971: 102-3).

Fil mito, en fin, ya configurado empiezat a actuar y su cometide primordial consiste en encubrir, en no dejar ver que Machado es problema, no solución, gue es pregunta, múltiples preguntals, y no respuesta, si acaso diversidacl de respuestas; que la obra de Machado está construida sobre una polifonía de voces, un espacio dialógico en el fue se dan cita elementos heterogéneos, contratios, contradictorios, que entran cn colisión sincrónica en su obra; un conjunto complejo de elementos fue no se deben relucir a la uniclad cle una esencial cue hatbla y actúa. Porque Machado es poeta del yo descentrado, desplazado, escindido, poeta de la 


\section{ANTONIO SÁNCHE7. TRI(GUHROSS}

alteridad. de la distancia, de la ironía, ciel heterónimo, máscara y disfraz, que simultáncamente propone la sutura de la herida social, la superación de la división, de la lucha de clases, por medio de la vuelta al yo-hombre esencial, (jue, encarnades en la expresión profunda de lo literario, restablece la perdida uniclad del ser, buceando en el Volkgeist. Machado, pues, nudo de contradicciones en lucha, que sólo pueden ser estudiadas y entendidas a la luz de su tiempo histórico, un tiempo de crisis resuclta sólo problentaticamente, descentradamente, en la obra de quien era no un taumaturgo ni un demiurgo, sino un hombre, y un hombre, como escenificó Brecht, es eso, sólo un hombre. Ĺsa es su servidumbre y ésa es su grandera: «Vio Machado tan lejos y fue lan lejos que se (lejó atrás a sí mismo» (Valente, 1971: 91).

\section{Referencias bibliográficas}

Comín, Alfonso Carlos (1966): "Dos inspiradores del diálogo: Mounier y Machado». Cimdernos para el Diálogo, noviembre, n." 38.

Conte, Rafacl (1989): "La poesía se hace historia». lil País, suplemento Extra, 22 de febrero.

Díe de Revengal, F. Javier (1989): «Un poeta auténtico». Cinculernos ('ompus, Murcia, marzo, $11 . " 1$.

Eiliade, Mircea (1968): Mito y recalidad. Madrid, Guaklarrama.

(iil Novales, Alberto (1966): Antonio Machudo. Barcelona, Fontanella.

(ioylisolo, Juan (1985): "Modernidad y dogmatismo: Jdanov, Joyec y Machado». Quimera. n." 43.

Iglesias, Amalia (1989): "Hombre y poeta». Diario 10. suplemento Culturas, 18 de febrero, II." 197.

Martíne\% Sarrión, Antonio (1989): «Ni una aspirina parat estar Iozano». lal País, suplemento kivra. 22 de febrero.

Molina, Juan (1989): «Un repicfue de campanas». Ya. 18 de febrero.

Paramio, Luclolfo (1971): Mito é ieleolegía. Madride. Alberto Corarán.

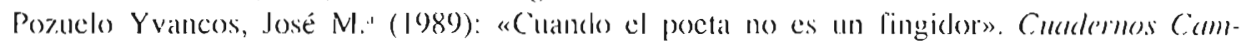
pus, Murcia, marro, n." 1.

Ridruejo, Dionisio (1940): «lil poctat rescatado». Escorial. noviembre.

Roxlríguez, T:mma (1989): «Primeras páginas poéticas». Ya. 18 de febrero.

Tuñón de Lara, Manuel (1967): Antemio Machade, peeta del pueblo. Barcelona, Nova T'erra.

Valente, José Ángel (1971): Las palabras de la tribu. Madrid, Siglo XXI. 